Article

\title{
Field Experiments on 10 kV Switching Shunt Capacitor Banks Using Ordinary and Phase-Controlled Vacuum Circuit Breakers
}

\author{
Wenxia Sima ${ }^{1}$, Mi Zou ${ }^{1}$ *, Qing Yang ${ }^{1}$, Ming Yang ${ }^{1}$ and Licheng Li $^{2}$ \\ 1 State Key Laboratory of Power Transmission Equipment \& System Security and New Technology, \\ Chongqing University, Chongqing 400044, China; cqsmwx@cqu.edu.cn (W.S.); \\ yangqing@cqu.edu.cn (Q.Y.); cqucee@cqu.edu.cn (M.Y.) \\ 2 School of Electric Power, South China University of Technology, Guangdong 510640, China; lilc@csg.cn \\ * Correspondence: zoumi@cqu.edu.cn; Tel.: +86-23-6511-1795 (ext. 8307); Fax: +86-23-6510-2442 \\ Academic Editor: Ying-Yi Hong \\ Received: 17 December 2015; Accepted: 27 January 2016; Published: 30 January 2016
}

\begin{abstract}
During the switching on/off of shunt capacitor banks in substations, vacuum circuit breakers (VCBs) are required to switch off or to switch on the capacitive current. Therefore, the VCBs have to be operated under a harsh condition to ensure the reliability of the equipment. This study presents a complete comparison study of ordinary and phase-controlled VCBs on switching $10 \mathrm{kV}$ shunt capacitor banks. An analytical analysis for switching $10 \mathrm{kV}$ shunt capacitor banks is presented on the basis of a reduced circuit with an ungrounded neutral. A phase selection strategy for VCBs to switch $10 \mathrm{kV}$ shunt capacitor banks is proposed. Switching on current waveforms and switching off overvoltage waveforms with, and without, phase selection were measured and discussed by field experiments in a $110 \mathrm{kV}$ substation in Chongqing, China. Results show that the operation of phase-controlled VCBs for $10 \mathrm{kV}$ switching shunt capacitor banks is stable, and phase-controlled VCBs can be used to implement the $10 \mathrm{kV}$ switching on/off shunt capacitor banks to limit the transient overvoltage and overcurrent. The values of overvoltage and inrush current using phase-controlled VCBs are all below those with ordinary VCBs.
\end{abstract}

Keywords: vacuum circuit breakers (VCBs); phase selection; shunt capacitor banks; field tests

\section{Introduction}

Switching shunt capacitor banks is the most widespread method for the compensation of reactive power or for the stabilization of voltage for power quality reasons [1-6]. Circuit breakers are usually switched to adjust the reactive power capacity according to the load change. Capacitive switching is conducted with an almost daily frequency according to an inquiry performed by the CIGRE (International Council on Large Electric systems) Working Group 13.04 in 1999 [7]. About 60\% of all capacitor banks are switched up to 300 times a year, and an additional 30\% are switched up to 700 times a year. Capacitor-switching transients have caused many problems for the past few years [8-14]. Among these problems, the capacitors bearing switching overvoltage may be the most direct and severe one. Thus, studying the effect of capacitor-switching transients on capacitors is essential.

In China, some $220 \mathrm{kV}$ power substations (especially in Hainan, an island in Southern China) or most $500 \mathrm{kV}$ series compensation station do not directly offer power supply to the users, and their $10 \mathrm{kV}$ busbars are not usually connected to the industry loads or the other loads. Substation transformer and reactive compensation equipment are connected to $10 \mathrm{kV}$ busbars in most of these substations. According to the fault statistics report from Chongqing electric power corporation, the faults caused by $10 \mathrm{kV}$ switching transients are always under the condition with no load or light loads. Thus, 
the condition of no load or light loads will be more severe to the safety of power system and equipment during the switching transients.

In a $10 \mathrm{kV}$ ungrounded neutral system, switching shunt capacitor banks often caused severe insulation faults of shunt capacitor banks or dry type transformers in China in recent years $[15,16]$. For example, in our previous work on switching shunt capacitor banks and shunt reactors [15,16], $12 \mathrm{kV}$ vacuum circuit breakers (VCBs) were used, and capacitor explosion occurred during our field experiments on switching $10 \mathrm{kV}$ shunt capacitor banks using ordinary VCBs in Chongqing, China, as shown in Figure 1. After checking the burnt capacitor body, we found that the failure was caused by a breakdown between the two terminals of the capacitors. Overvoltage was deemed as the main reason of this accident. Therefore, based on our previous study and experience in this field, in a $10 \mathrm{kV}$ ungrounded system, we proposed that the VCBs with phase selection was a potential and alternative method to limit the overvoltage and overcurrent caused by switching shunt capacitor banks.

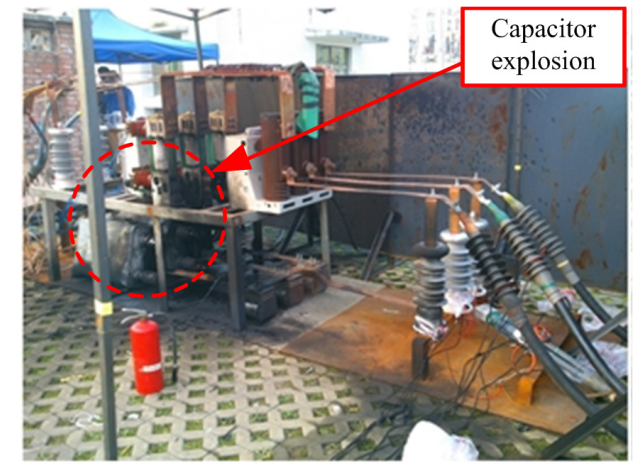

(a)

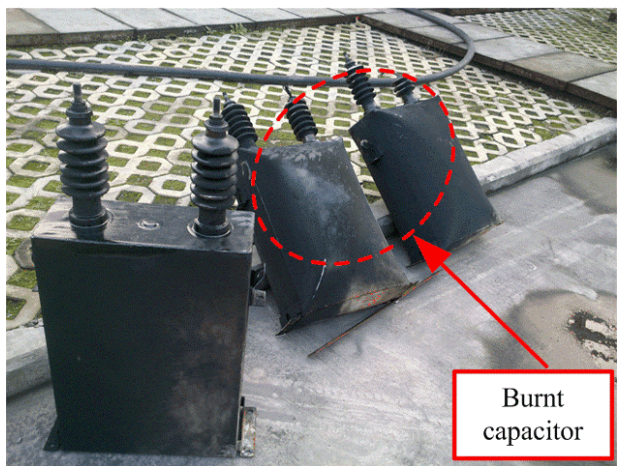

(b)

Figure 1. An explosion involving switching $10 \mathrm{kV}$ shunt capacitor banks with vacuum circuit breakers (VCBs). (a) Testing site; and (b) burnt capacitors.

Even though the transient duration is usually very short, switching shunt capacitor banks produces harmful transients which can reduce the life of the devices [17,18]. Conventionally, pre-insertion resistors or inductors, and $\mathrm{R}-\mathrm{C}$ snubber circuits, have been applied to limit the switching transients during opening or closing shunt capacitor banks $[19,20]$. These methods may have reduced or limited the switching overvoltage and transients to some extent. However, pre-insertion resistors will dissipate energy and release a large amount of heat, and the operation of pre-insertion inductors may cause electric sparks and bring about resonance. Pre-insertion resistors or inductors will also result in increasing equipment costs and may not provide appreciable transient reduction $[18,21]$. The method of R-C snubber circuits may bring about severe harmonic distortion [21,22]. Thus, an alternative, more economical, and effective approach to reduce and limit the switching overvoltage and transients is phase-controlled switching. The significant advantages of phase-controlled switching include limitation of closing inrush currents, suppression of switching overvoltages, lower rate of power equipment failures and less maintenance of frequently used circuit breakers [17,19,23]. CIGRE Working Group A3-07 presented a series of studies on the development and application of VCBs with phase selection $[17,24]$. According to their statistical data, circuit breakers with phase selection have been widely used in $26.4-800 \mathrm{kV}$ power systems, and about $64 \%$ of all circuit breakers with phase selection are applied to switch shunt capacitor banks. Many theoretical and simulation studies on the overvoltage and insulation failures caused by switching shunt capacitor banks have been reported [25-28]. However, only a few studies have been done on the comparison and application of ordinary and phase-controlled VCBs in substation by field tests. For this reason, field measurements of switching $10 \mathrm{kV}$ shunt capacitor banks have been conducted with the use of both ordinary VCBs and phase-controlled VCBs to compare the opening overvoltage and closing current caused by $10 \mathrm{kV}$ switching shunt capacitor banks. 
The main contribution of this study is to investigate and demonstrate the potential effects and advantages of phase-controlled VCBs in $10 \mathrm{kV}$ switching transients instead of $110 \mathrm{kV}$ system, when compared with the ordinary VCBs. The rest of this paper is organized as follows. In Section 2, the overvoltage and the overcurrent of switching $10 \mathrm{kV}$ Y-connected shunt capacitor banks are analyzed by analytical method based on a simplified circuit. In Section 3, a phase-selecting control strategy for VCBs to switch on or to switch off capacitor banks is proposed. In Section 4, six typical cases of field experiments are compared and discussed. Lastly, the conclusion is presented in Section 5.

\section{Analytical Analysis}

The analytical analysis of switching shunt capacitor banks is studied. Figure 2a illustrates the switching shunt capacitor bank circuit for an ungrounded power system with Y-connected shunt capacitor banks. $U_{\mathrm{sa}}(t), U_{\mathrm{sb}}(t)$, and $U_{\mathrm{sc}}(t)$ are the power sources. $R$ is the internal resistance of source. $K_{\mathrm{a}}, K_{\mathrm{b}}$, and $K_{\mathrm{c}}$ are the circuit breakers. $L$ is the series inductance, and $C$ are the shunt capacitor banks. In a $10 \mathrm{kV}$ ungrounded neutral system, the typical values of these parameters are as follows: $U_{\mathrm{sa}}(t)=8.165 \sin (100 \pi t) \mathrm{kV}, U_{\mathrm{sb}}(t)=8.165 \sin \left(100 \pi t+120^{\circ}\right) \mathrm{kV}$, $U_{\mathrm{sc}}(t)=8.165 \sin \left(100 \pi t-120^{\circ}\right) \mathrm{kV}, R=0.2 \Omega, C=27.14 \mu \mathrm{F}, L=9.90 \mathrm{mH}$. The reduced circuit in Figure $2 \mathrm{~b}$ can be obtained with the assumption of simultaneous switching on/off for the three-phase circuit breakers.

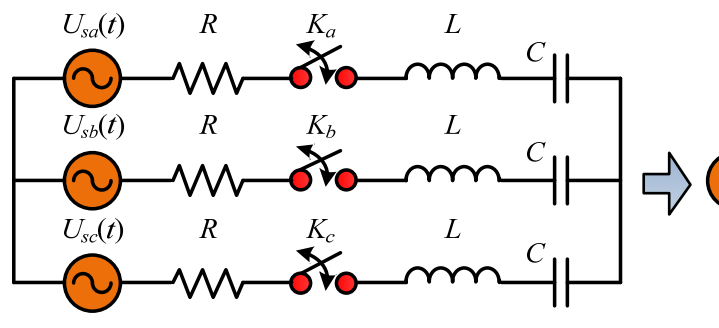

(a)

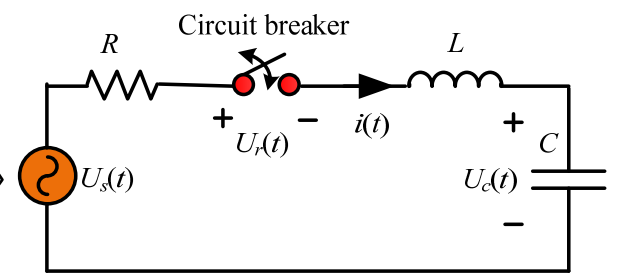

(b)

Figure 2. Circuit of switching shunt capacitor banks. and $(\mathbf{b})$ reduced circuit.

\subsection{Closing Operation}

According to the principle of Kirchhoff's voltage law and initial conditions, Equation (1) can be obtained as:

$$
L C \frac{\mathrm{d}^{2} U_{\mathrm{c}}(t)}{\mathrm{d} t^{2}}+R C \frac{\mathrm{d} U_{\mathrm{c}}(t)}{\mathrm{d} t}+U_{\mathrm{c}}(t)=U_{\mathrm{s}}(t)
$$

where $U_{\mathrm{s}}(t)=U_{\mathrm{sm}} \sin \left(\omega t+\theta_{\mathrm{c}}\right), \omega$ is the angular frequency of source, $\theta_{\mathrm{c}}$ is the closing phase angle, and $U_{\mathrm{sm}}$ is the source voltage amplitude.

With $\theta_{\mathrm{c}}=90^{\circ}$, the solutions for Equation (1) are given as follows:

$$
\begin{gathered}
U_{\mathrm{c}}(t)=U_{\mathrm{cm}} \cos (\omega t)+\left(U_{0}-U_{\mathrm{cm}}\right) \cos \left(\omega_{0} t\right) \\
i_{\mathrm{c}}(t)=C \frac{\mathrm{d} U_{\mathrm{c}}(t)}{\mathrm{d} t}=-U_{\mathrm{cm}} \omega C \sin (\omega t)-\frac{\left(U_{0}-U_{\mathrm{cm}}\right)}{\sqrt{L / C}} \sin \left(\omega_{0} t\right)
\end{gathered}
$$

where $U_{0}$ is the value of the initial capacitor voltage, $U_{\mathrm{cm}}$ is the steady voltage of capacitor $U_{\mathrm{cm}}=\frac{U_{\mathrm{sm}}}{\omega C \sqrt{R^{2}+(\omega L-1 / \omega C)^{2}}}, \omega_{0}=1 / \sqrt{(L C)}$, and $\omega_{0}$ is the oscillation frequency. The amplitude of the closing current and voltage are given as:

$$
\left|U_{\mathrm{cmax}}\right|=\left|2 U_{\mathrm{cm}}-U_{0}\right|
$$




$$
i_{\mathrm{cmax}}=I_{\mathrm{cm}}\left(1+f_{0} / f\right)
$$

where $I_{\mathrm{cm}}$ is the steady current of capacitor banks $I_{\mathrm{cm}}=\frac{U_{\mathrm{sm}}}{\sqrt{R^{2}+(\omega L-1 / \omega C)^{2}}}, f_{0}=\omega_{0} / 2 \pi$, and $f_{0} \geqslant 500 \mathrm{~Hz}$ in the most serious case. Thus, the closing overvoltage is below $2.0 U_{\mathrm{cm}}$, and the closing current may reach $11 I_{\mathrm{cm}}$ in the most serious case.

With $\theta_{\mathrm{c}}=0^{\circ}$, the amplitude of the closing current and voltage are given in the same way as:

$$
\begin{gathered}
U_{\mathrm{cmax}}=U_{\mathrm{sm}}\left(1+f / f_{0}\right) \\
\left|i_{\mathrm{cmax}}\right|=\left|2 I_{\mathrm{cm}}-I_{0}\right|
\end{gathered}
$$

where $I_{0}$ is the value of the initial capacitor current. Therefore, closing at $\theta_{c}=0^{\circ}$ significantly decreases the closing current by comparing Equation (7) with Equation (5).

\subsection{Opening Operation}

When the moving and static contacts are separated, $U_{\mathrm{c}}(t)$ is almost equal to $U_{\mathrm{s}}(t)$ because the arc voltage and inductance voltage are very low $(j \omega L=1 / j \omega C \times 5 \%)$. The capacitor voltage will be maintained at $U_{\mathrm{sm}}$ after arc extinguishing if capacitor the discharge is ignored. The transient recovery voltage of the circuit breaker contacts will be as follows:

$$
U_{\mathrm{r}}(t)=U_{\mathrm{s}}(t)-U_{\mathrm{sm}}=U_{\mathrm{sm}}[\sin (\omega t+\pi / 2)-1]
$$

$U_{\mathrm{r}}(t)$ is equal to $-2 U_{\mathrm{sm}}$ after half a cycle $(\omega t=\pi)$. If the dielectric recovery voltage is less than $2 U_{\mathrm{sm}}$ at this moment, the re-striking and subsequent high-frequency oscillation will occur. The high-frequency voltage and current of the capacitor are given as follows:

$$
\left\{\begin{array}{l}
U_{\mathrm{c}}(t)=U_{\mathrm{sm}}-2 U_{\mathrm{sm}} \cos \left(\omega_{0} t\right) \\
i_{\mathrm{c}}(t)=C \frac{\mathrm{d} U_{\mathrm{c}}(t)}{\mathrm{d} t}=2 \omega_{0} C U_{\mathrm{sm}} \sin \left(\omega_{0} t\right)
\end{array}\right.
$$

The overvoltage of the capacitor is equal to $3 U_{\mathrm{sm}}$ at $i_{\mathrm{c}}(t)$ initially crossing zero during high-frequency oscillation. In the same moment, the overvoltage of capacitor will be maintained at $3 U_{\mathrm{sm}}$ if the arc extinguishes. After a half cycle, the transient recovery voltage of the contacts reaches $4 U_{\mathrm{sm}}$. If re-striking occurs again, the maximum value of $U_{\mathrm{c}}(t)$ will reach $5 U_{\mathrm{sm}}$. With this analogy, the overvoltage of the capacitor becomes 3 p.u., 5 p.u., 7 p.u., and so on.

It should be noted that, however, in practical switching operation, the switching operation time cannot be completely consistent because of the switching time scatter of three-phase vacuum breakers. In a $10 \mathrm{kV}$ ungrounded system, shunt capacitor banks are always in Y-type ungrounded neutral in China; random non-simultaneously switching generally will result in a shift of the voltage of the neutral point of the capacitor banks, higher overvoltage and overcurrent on capacitors and circuit breakers, and more complicated oscillation [29,30]. In particular, the overvoltage and overcurrent of the last switching pole will be affected by the switching angle, delay time and line-to-line voltage of the other two phases [29,30]. Thus, in $10 \mathrm{kV}$ ungrounded system, the phase-controlled switching method is proposed in this study to limit the overvoltage and transients.

\section{Phase-Selecting Control Strategy for $10 \mathrm{kV}$ Ungrounded Capacitor Banks}

The structure of phase-controlled VCBs used in this experiment (MDS2B-12) is presented. As depicted in Figure 3, the MDS2B-12 mainly consists of a separate three-pole permanent magnetic actuator $\mathrm{VCB}$, a three-pole phase selection intelligent controller, a power supply, a potential transformer testing capacitance residual voltage, and a telecommunications system.

The strategies and processes of switching shunt capacitor banks based on the phase-controlled methodology are analyzed, as shown in Figures 4 and 5. To reduce the closing inrush current for 
ungrounded shunt capacitor banks, the strategy for closing capacitor banks is to close the two phases while their phase voltages are equal and then to close the third phase while its phase voltage crosses zero ( $5 \mathrm{~ms}$ later than the above two phases). Figure 4 shows the sequence of closing capacitor banks with phase selection. Taking the line voltage of phase $A$ and phase $B$ as reference, the breaker receives the closing signal at $t_{0}$, the breakers of phase $\mathrm{A}$ and phase $\mathrm{B}$ close at $t_{\mathrm{ab}}$, and the breaker of phase $\mathrm{C}$ closes at $t_{\mathrm{c}} \cdot t_{\mathrm{Ad}}, t_{\mathrm{Bd}}$, and $t_{\mathrm{Cd}}$ are the closing delay times, respectively.

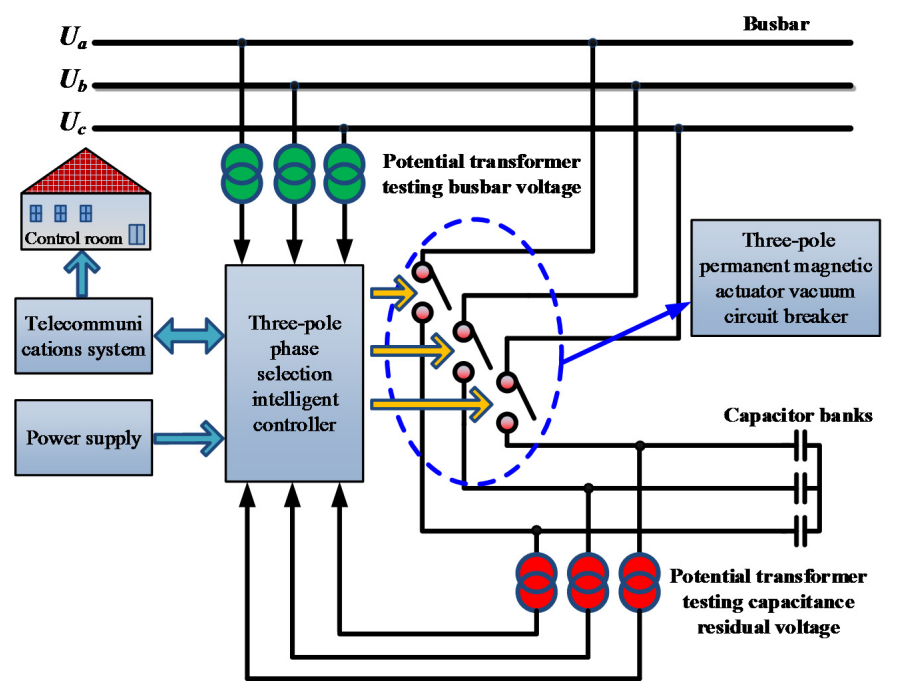

Figure 3. Structure chart of phase-controlled VCBs (MDS2B-12).

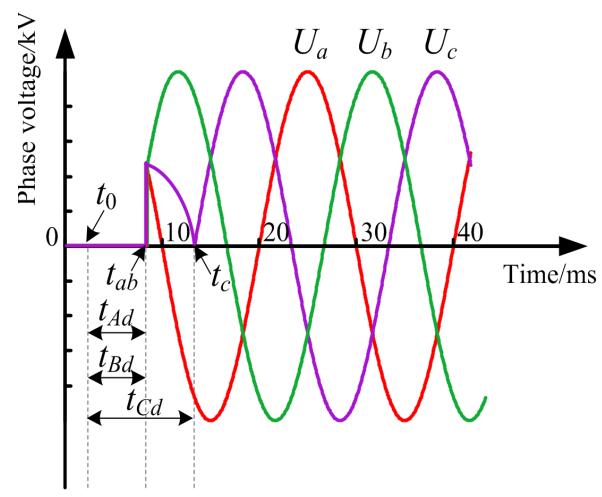

Figure 4. Sequence of closing capacitor banks with phase selection.

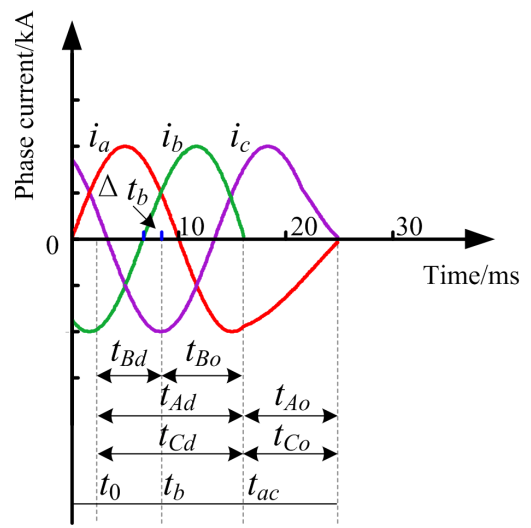

Figure 5. Sequence of opening capacitor banks with phase selection. 
The breakers should start to open a little earlier than the phase current crosses zero to ensure sufficient circuit breaker fracture gap distance $\left(\Delta t_{\mathrm{b}}\right.$ as shown in Figure 5$)$. The strategy for opening capacitor banks is to open one phase and then to open the other two phases when the current of the first-pole-to-clear reaches zero ( $5 \mathrm{~ms}$ later than the first phase). Figure 5 shows the sequence of opening capacitor banks with phase selection. The breaker receives the opening signal at $t_{0}$, the breaker of phase $\mathrm{B}$ opens at $t_{\mathrm{b}}$, and breakers of phase $\mathrm{A}$ and phase $\mathrm{C}$ opens at $t_{\mathrm{ac}} \cdot t_{\mathrm{Ad}}, t_{\mathrm{Bd}}$, and $t_{\mathrm{Cd}}$ are the opening delay times, respectively. $t_{\mathrm{Ao}}, t_{\mathrm{Bo}}$, and $t_{\mathrm{Co}}$ are the times between the moving contact starting to move and the moment the moving and static contacts are completely separated.

\section{Field Test Results and Discussion}

The field test of $10 \mathrm{kV}$ switching shunt capacitor banks is conducted on the $10 \mathrm{kV}$ side of a $110 \mathrm{kV}$ substation in Chongqing, China. The short circuit capacity for the $10 \mathrm{kV}$ system is $245 \mathrm{MVA}$, and the system short circuit reactance is $0.45 \Omega$. Figure 6 shows the site layout of the field experiment, and Figure 7 presents the corresponding test circuit. \#653 represents the ordinary VCBs, and \#65301, \#65302, and \#65303 represent the three groups of phase-controlled VCBs, respectively. The layout of the voltage measurement points (VMPs) and the current measurement points (CMPs) in the field test are also shown in Figure 7. The divider ratio of the capacitor voltage dividers is 350:1, and the frequency bandwidth of the capacitor dividers is from $50 \mathrm{~Hz}$ to $50 \mathrm{MHz}$. The current measurement range and the frequency bandwidth of the Rogowski coils are $0-6 \mathrm{kA}$ and $30 \mathrm{~Hz}-1 \mathrm{MHz}$, respectively. The parameters of the capacitors and inductors are shown in Table 1.

During the operation of ordinary VCBs and phase-controlled VCBs switching on and off the corresponding shunt capacitor banks, the signals from the Rogowski coils and capacitor voltage dividers are transferred to the signal processing unit. The signals are sampled and stored through a multichannel high-speed frequency conversion data acquisition card (maximum sampling frequency of up to $40 \mathrm{MHz}$ ) of a computer.
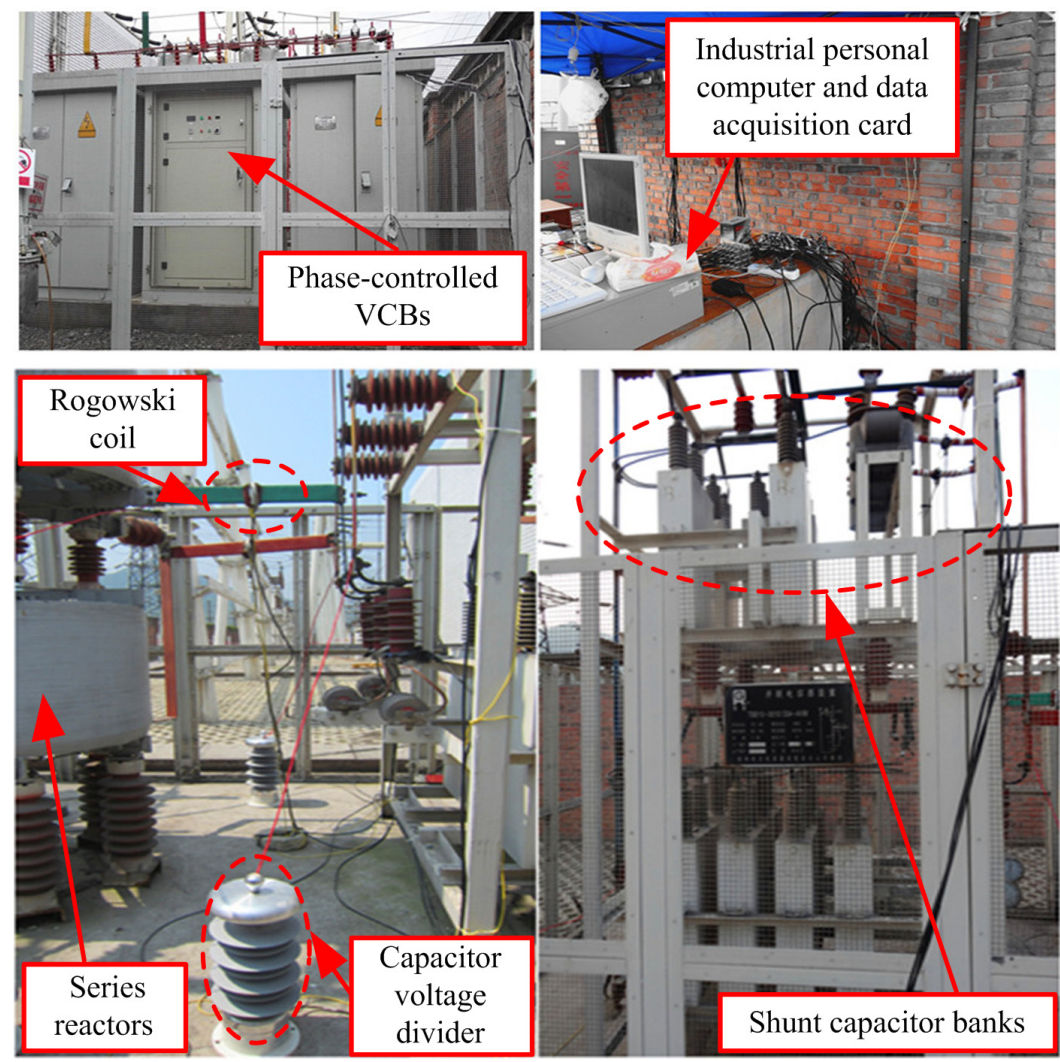

Figure 6. Site layout of the field tests in a $110 \mathrm{kV}$ substation. 


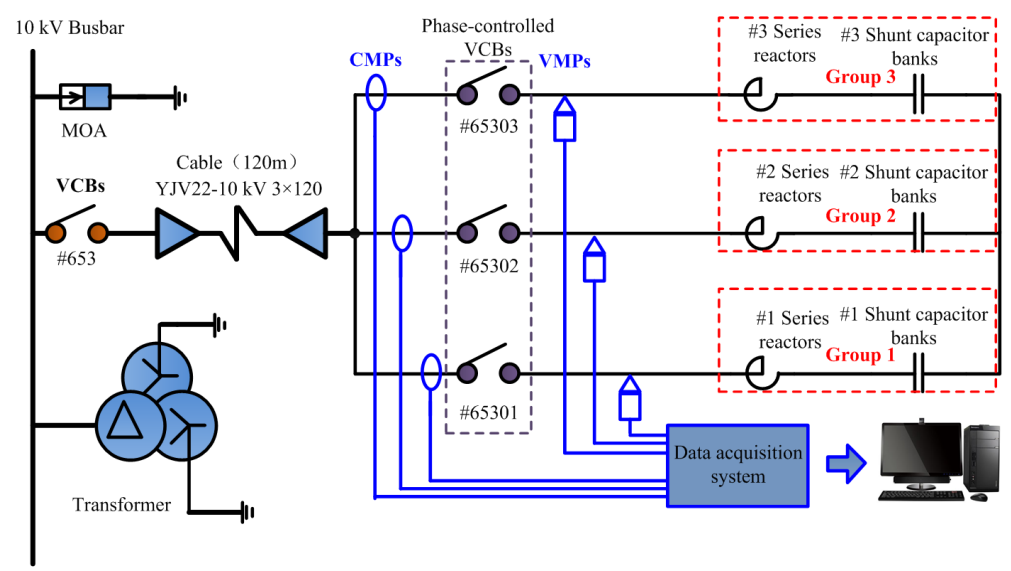

Figure 7. Test circuit of switching $10 \mathrm{kV}$ shunt capacitor banks in a $110 \mathrm{kV}$ substation.

Table 1. Parameters of the capacitors and reactors.

\begin{tabular}{ccccc}
\hline Parameters & Phase A & Phase B & Phase C & Total \\
\hline Power frequency & $50 \mathrm{HZ}$ & $50 \mathrm{HZ}$ & $50 \mathrm{HZ}$ & - \\
Rated power of capacitors & $2004 \mathrm{kVAR}$ & $2004 \mathrm{kVAR}$ & $2004 \mathrm{kVAR}$ & $6012 \mathrm{kVAR}$ \\
Number of capacitors & 6 & 6 & 6 & 18 \\
Number of groups & 3 & 3 & 3 & 9 \\
Number of capacitors in each group & 2 & 2 & 2 & 6 \\
Capacitance of each capacitor & $27.14 \mu \mathrm{F}$ & $27.14 \mu \mathrm{F}$ & $27.14 \mu \mathrm{F}$ & - \\
Rated voltage of each capacitor & $11 / \sqrt{3} \mathrm{kV}$ & $11 / \sqrt{3} \mathrm{kV}$ & $11 / \sqrt{3} \mathrm{kV}$ & - \\
Rated power of each capacitor & $334 \mathrm{kVAR}$ & $334 \mathrm{kVAR}$ & $334 \mathrm{kVAR}$ & - \\
Series reactor rate of shunt capacitor bank & $5 \%$ & $5 \%$ & $5 \%$ & $5 \%$ \\
Rated power of reactors & $100.2 \mathrm{kVAR}$ & $100.2 \mathrm{kVAR}$ & $100.2 \mathrm{kVAR}$ & $300.6 \mathrm{kVAR}$ \\
Number of reactors & 3 & 3 & 3 & 9 \\
Number of groups & 3 & 3 & 3 & 9 \\
Number of reactors in each group & 1 & 1 & 1 & 3 \\
Inductance of each reactor & $9.90 \mathrm{mH}$ & $9.90 \mathrm{mH}$ & $9.90 \mathrm{mH}$ & - \\
Rated voltage of each reactor & $10 \mathrm{kV}$ & $10 \mathrm{kV}$ & $10 \mathrm{kV}$ & - \\
Rated power of each reactor & $33.4 \mathrm{kVAR}$ & $33.4 \mathrm{kVAR}$ & $33.4 \mathrm{kVAR}$ & - \\
Quality factor (Q) of the reactor & 50 & 50 & 50 & - \\
\hline
\end{tabular}

The switching of the shunt capacitor banks are conducted 10 times by using phase-controlled VCBs (\#65301), and are conducted 12 times by ordinary VCBs (\#653). The operation of opening shunt capacitor banks is implemented after $5 \mathrm{~min}$ of closing the shunt capacitor banks. However, the operation of closing is conducted after $10 \mathrm{~min}$ of opening the shunt capacitor banks to fully discharge the capacitor banks. Six different typical cases are analyzed and discussed, as shown in Table 2 and Figures 8-13. It should be noted that, in Cases 2 and 5, the three groups of capacitor banks are simultaneously switched. The main reason of these two cases is to make a comparison with Cases 1 and 4 , in which the shunt capacitors are also switched by ordinary VCBs, to investigate the impact of capacitor compensation capacity on the switching overvoltage, overcurrent, and transient.

Table 2. Typical cases of switching $10 \mathrm{kV}$ shunt capacitor banks.

\begin{tabular}{cccccc}
\hline No. & Operation & Breaker & Group & Voltage Base Value (kV) & Current Base Value (A) \\
\hline Case 1 & Switching on & Without phase selection (\#653) & 1 & 8.165 & 155.56 \\
Case 2 & Switching on & Without phase selection (\#653) & $1-3$ & 8.165 & 466.69 \\
Case 3 & Switching on & With phase selection (\#65301) & 1 & 8.165 & 155.56 \\
Case 4 & Switching off & Without phase selection (\#653) & 1 & 8.165 & 155.56 \\
Case 5 & Switching off & Without phase selection (\#653) & $1-3$ & 8.165 & 466.69 \\
Case 6 & Switching off & With phase selection (\#65301) & 1 & 8.165 & 155.56 \\
\hline
\end{tabular}


The peak line-to-neutral voltage of $10 \mathrm{kV}$ power systems is as follows [16,31]:

$$
U_{\text {peak }}=10 \times \sqrt{2} / \sqrt{3}=8.165 \mathrm{kV}
$$

\subsection{Case 1}

Before the switching-on operations in Case 1, \#65302 and \#65303 are opened, and \#65301 is closed. The circuit breaker of this switching operation is \#653. Figure 8a shows the closing current waveform of Case 1 without phase selection. The maximum value of the closing current in this case occurs in phase B, and its value is $0.63 \mathrm{kA}$ (4.04 p.u.). The duration of the closing shunt capacitor banks' current transient is about 110-120 ms, and the high-frequency oscillation frequency of the closing shunt capacitor banks' current is about $198 \mathrm{~Hz}$.

Figure $8 \mathrm{~b}$ illustrates corresponding closing voltage waveforms in Case 1 . The maximum of the closing voltage is $10.08 \mathrm{kV}$ (1.23 p.u.). The duration of the closing shunt capacitor banks' voltage transient is only $20 \mathrm{~ms}$.
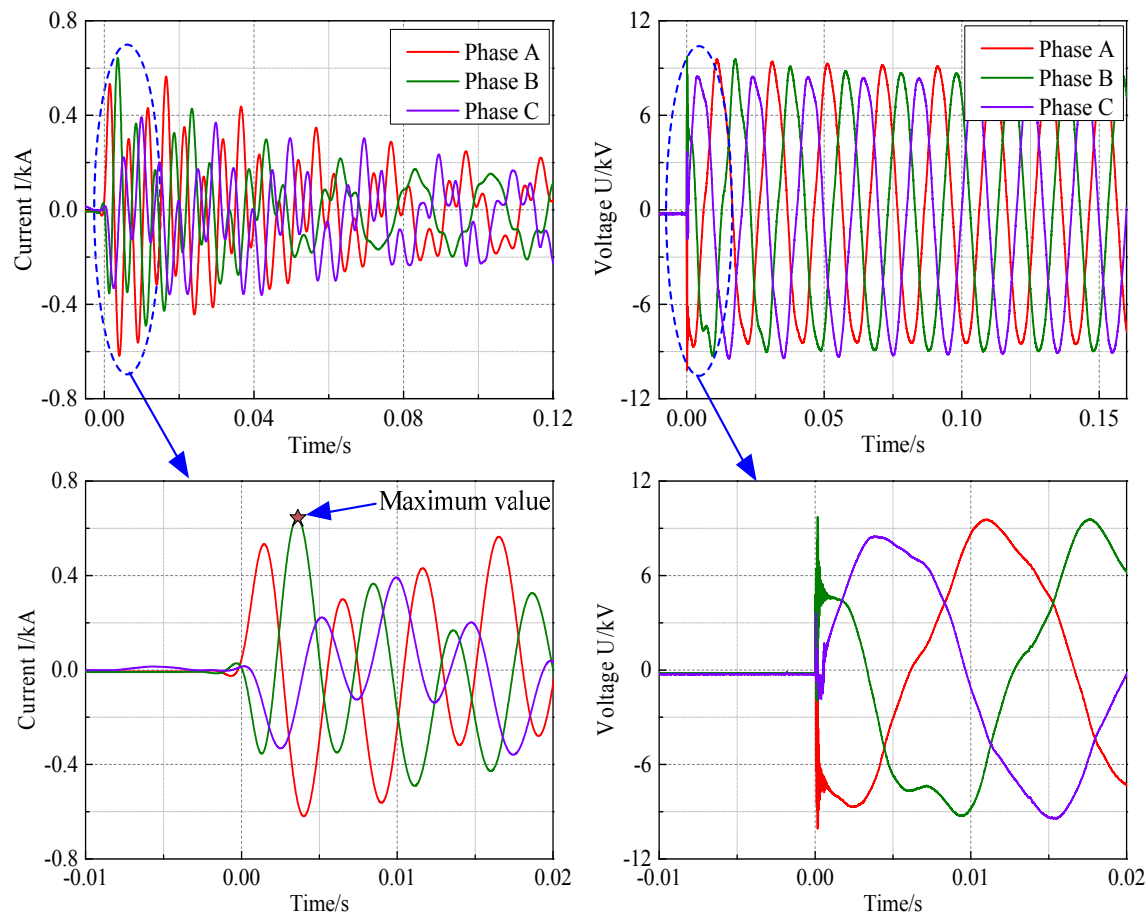

(b)

Figure 8. Waveforms of the closing current and capacitor voltage in Case 1. (a) Current waveform; and (b) voltage waveform.

\subsection{Case 2}

Before the switching-on operations in Case 2, \#65301, \#65302, and \#65303 are all closed. The circuit breaker of this switching operation is also \#653. Figure 9a shows the closing current waveform in Case 2 without phase selection but with three groups of shunt capacitor banks. The maximum value of the closing current in this case occurs in phase $\mathrm{A}$, and its value is $-2.09 \mathrm{kA}$ (4.49 p.u.). The duration of the closing shunt capacitor banks' current transient is about $90-100 \mathrm{~ms}$, and the high-frequency oscillation frequency of the closing shunt capacitor banks' current is about $192 \mathrm{~Hz}$ in this case.

Figure $9 \mathrm{~b}$ illustrates the corresponding closing voltage waveforms in Case 2 . The maximum of the closing voltage also occurs in phase $\mathrm{A}$, and its value is $14.25 \mathrm{kV}$ (1.75 p.u.). The voltage transient reaches the steady state after about $20 \mathrm{~ms}$. 

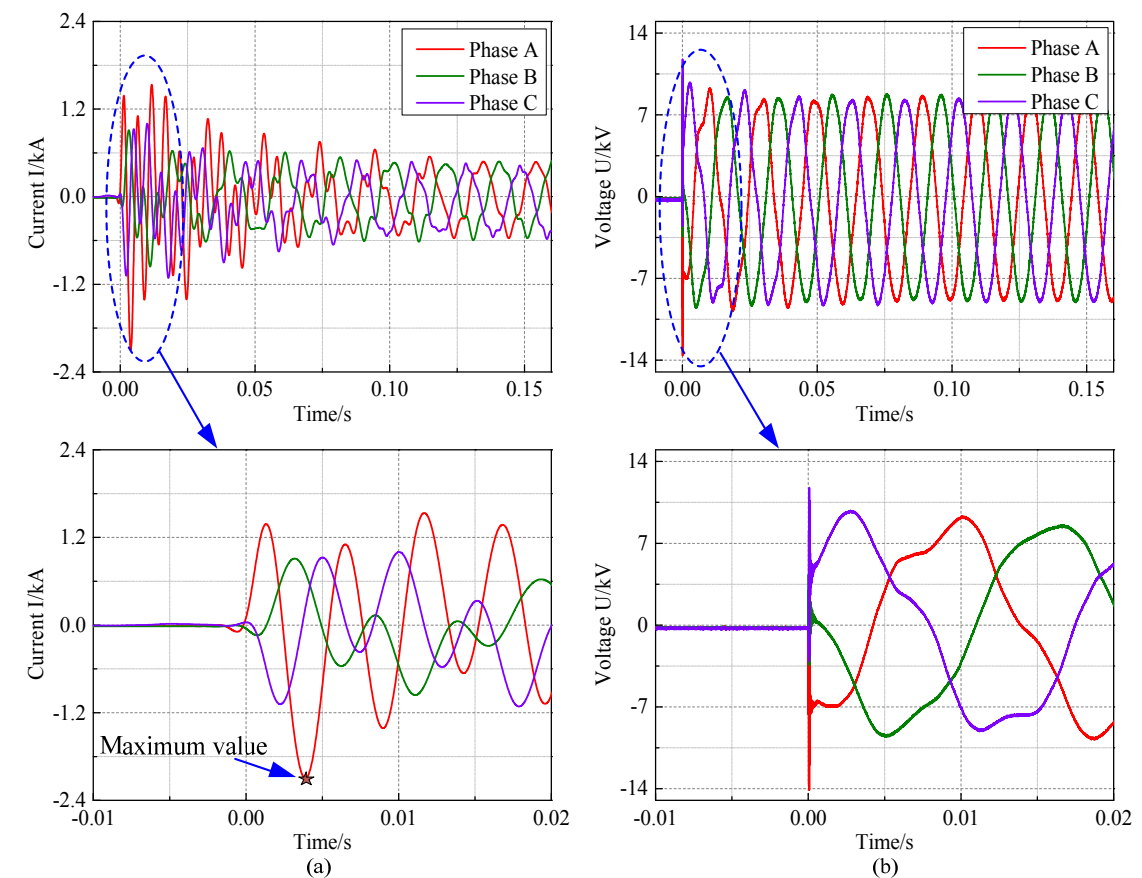

Figure 9. Waveforms of the closing current and capacitor voltage in Case 2. (a) Current waveform; and (b) voltage waveform.

\subsection{Case 3}

Before the switching-on operations in Case 3, \#653 is closed, and \#65302 and \#65303 are opened. The circuit breaker of this switching operation is \#65301. Figure 10a shows the closing current waveform in Case 3 with phase selection. The strategy of the closing shunt capacitor banks with phase selection is addressed in Section 2. The maximum value of the closing current in this case occurs in phase A, and its value is $0.33 \mathrm{kA}$ (2.12 p.u.). The duration of the closing shunt capacitor banks' current transient is about $100-110 \mathrm{~ms}$, and the high-frequency oscillation frequency of the closing shunt capacitor banks' current is about $206 \mathrm{~Hz}$ in this case.

Figure 10b illustrates the corresponding closing voltage waveforms. As shown in Figure 10b, phase $\mathrm{A}$ and phase $\mathrm{B}$ are closed at $t_{1}$ when their line voltage $U_{\mathrm{ab}}$ crosses zero, and then phase $\mathrm{C}$ is closed after $5 \mathrm{~ms}$ at $t_{2}$ when its phase voltage crosses zero. The transient voltage of phase $\mathrm{C}$ from $t_{1}$ to $t_{2}$ is equal to the neutral voltage of the shunt capacitor banks. Thus, the zero-crossing switching strategy is achieved. Almost no high-frequency voltage oscillation occurs in this case, and the corresponding maximum of the high-frequency oscillation voltage is very low (about 0.76 p.u.). The time error of the phase-controlled circuit breaker for closing the shunt capacitor banks is below $\pm 0.2 \mathrm{~ms}$.

\subsection{Case 4}

Before the switching-off operations in Case 4, \#65302 and \#65301 are opened, and \#65301 is closed. The circuit breaker of the switching operation is \#653. Figure 11a shows the opening current waveform in Case 4 without phase selection. The breaker contacts of phase B start to separate at $t_{3}$, and phase B is the first-pole-to-clear. The transient currents of phase $\mathrm{A}$ and phase $\mathrm{C}$ are always equal, but in the opposite direction, after the current of phase $\mathrm{B}$ decreases to zero at the moment of $t_{4}$, which is also the time of the contacts of phase $\mathrm{A}$ and phase $\mathrm{C}$ start to separate. The breaking arc duration of phase $\mathrm{B}$ is $\Delta t_{1}=1.7 \mathrm{~ms}\left(\Delta t_{1}=t_{4}-t_{3}\right)$. After a quarter of a cycle $(5 \mathrm{~ms})$, the currents of phase A and phase $\mathrm{C}$ both reach zero at the moment of $t_{5}$. Thus, the phenomenon of the power frequency extinguishing arcing is observed. Statistical results according to our field tests show that the breaking arc duration of the first-pole-to-clear (phase B in this test) is almost $1.0-4.5 \mathrm{~ms}$. 
Figure $11 \mathrm{~b}$ illustrates the corresponding opening voltage waveforms in Case 4 . The maximum of the opening voltage in this case occurs in the first-pole-to-clear (phase B), and its value is $18.45 \mathrm{kV}$ (2.26 p.u.). Residual charge of the capacitors remains more than 30 power frequency cycles after the capacitors are disconnected. Thus, the switching off operation is 10 min later.
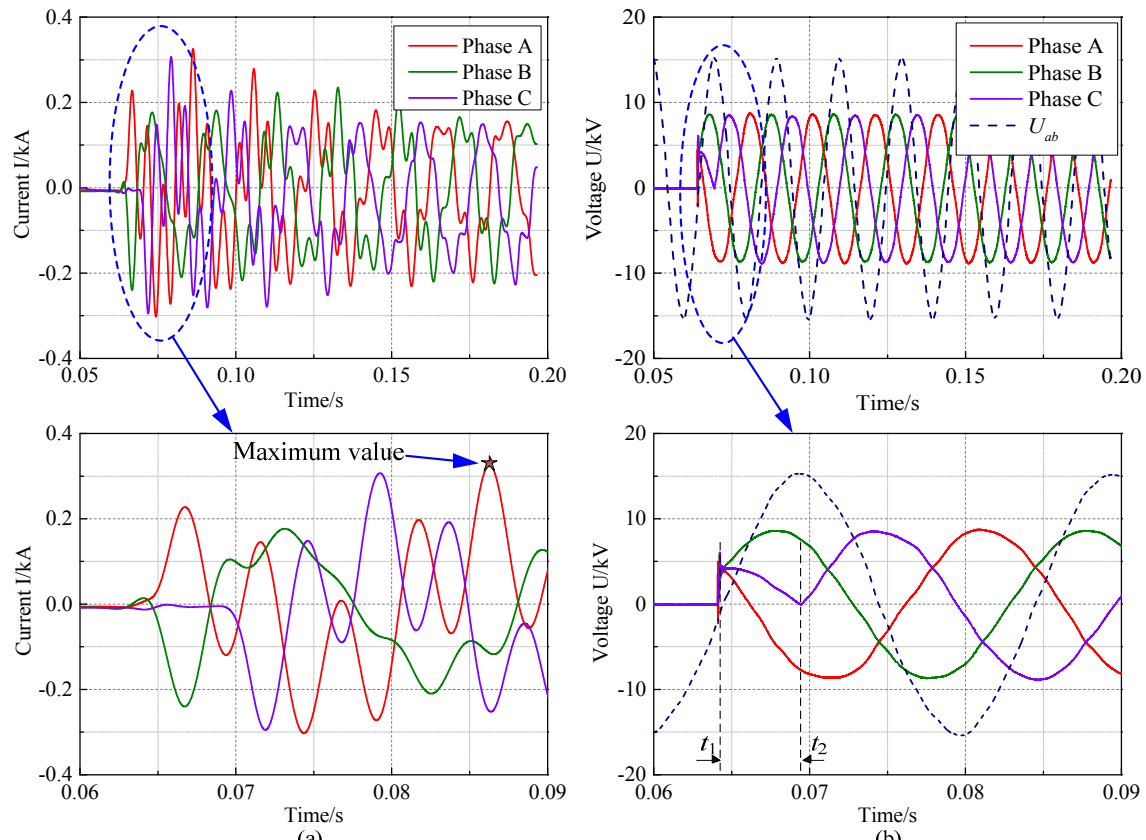

(b)

Figure 10. Waveforms of the closing current and capacitor voltage in Case 3. (a) Current waveform; and (b) voltage waveform.
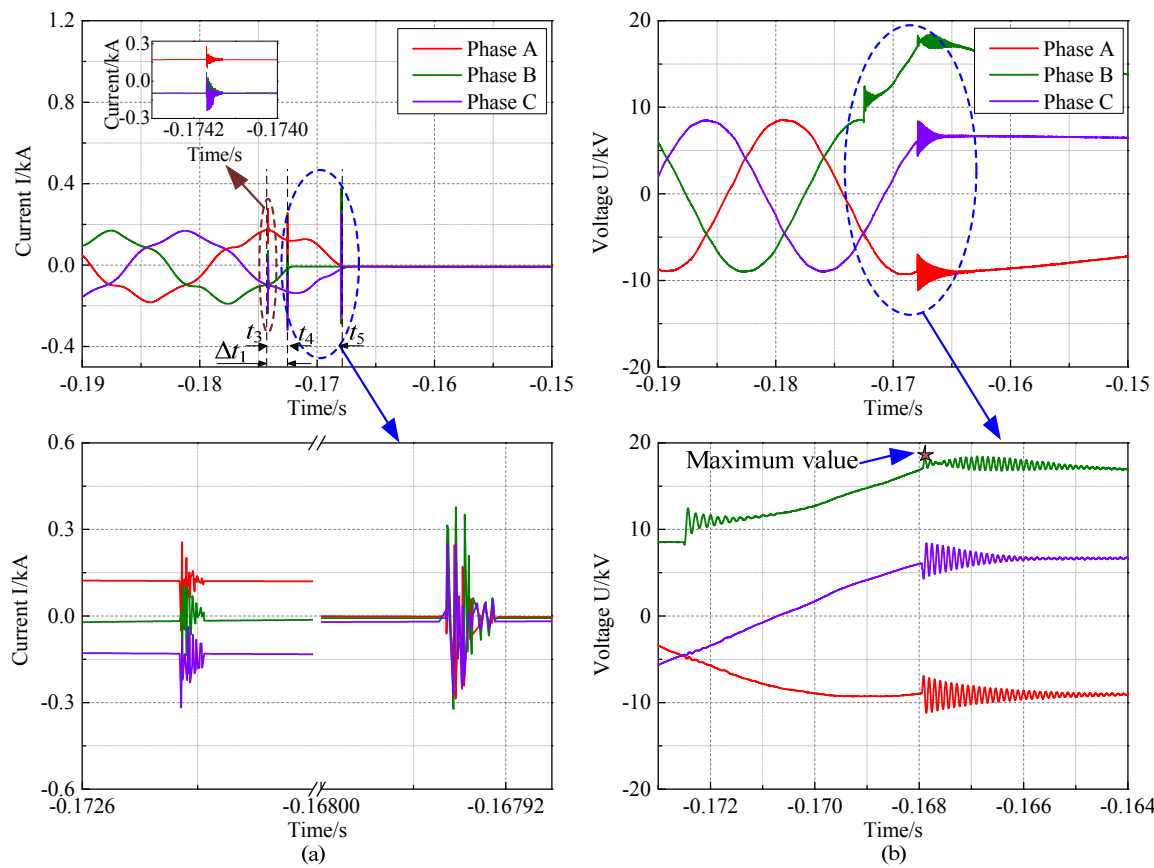

Figure 11. Waveforms of the opening current and capacitor voltage in Case 4. (a) Current waveform; and (b) voltage waveform. 


\subsection{Case 5}

Before the switching-off operations in Case 5,\#65301,\#65302, and \#65303 are all closed. The circuit breaker of this switching operation is still \#653. Figure 12a shows the opening shunt capacitors banks' current waveform in Case 5 without phase selection but with three groups of shunt capacitor banks. The breaker contacts of phase B start to separate at $t_{6}$, and phase B is also the first-pole-to-clear. The breaking arc duration of phase B is $\Delta t_{2}=4.1 \mathrm{~ms}\left(\Delta t_{2}=t_{7}-t_{6}\right)$. The currents of phases $\mathrm{A}$ and $\mathrm{C}$ are equal but opposite in direction from $t_{7}$ to $t_{8}$, during which the current of phase B reaches zero. After $t_{8}$, the currents of the three phases remain zero.

Figure $12 \mathrm{~b}$ shows the opening voltage waveforms in Case 5 . The maximum value of the opening voltage is $-18.20 \mathrm{kV}$ (2.23 p.u.), and it still occurs in the first-pole-to-clear (phase B) in this case.
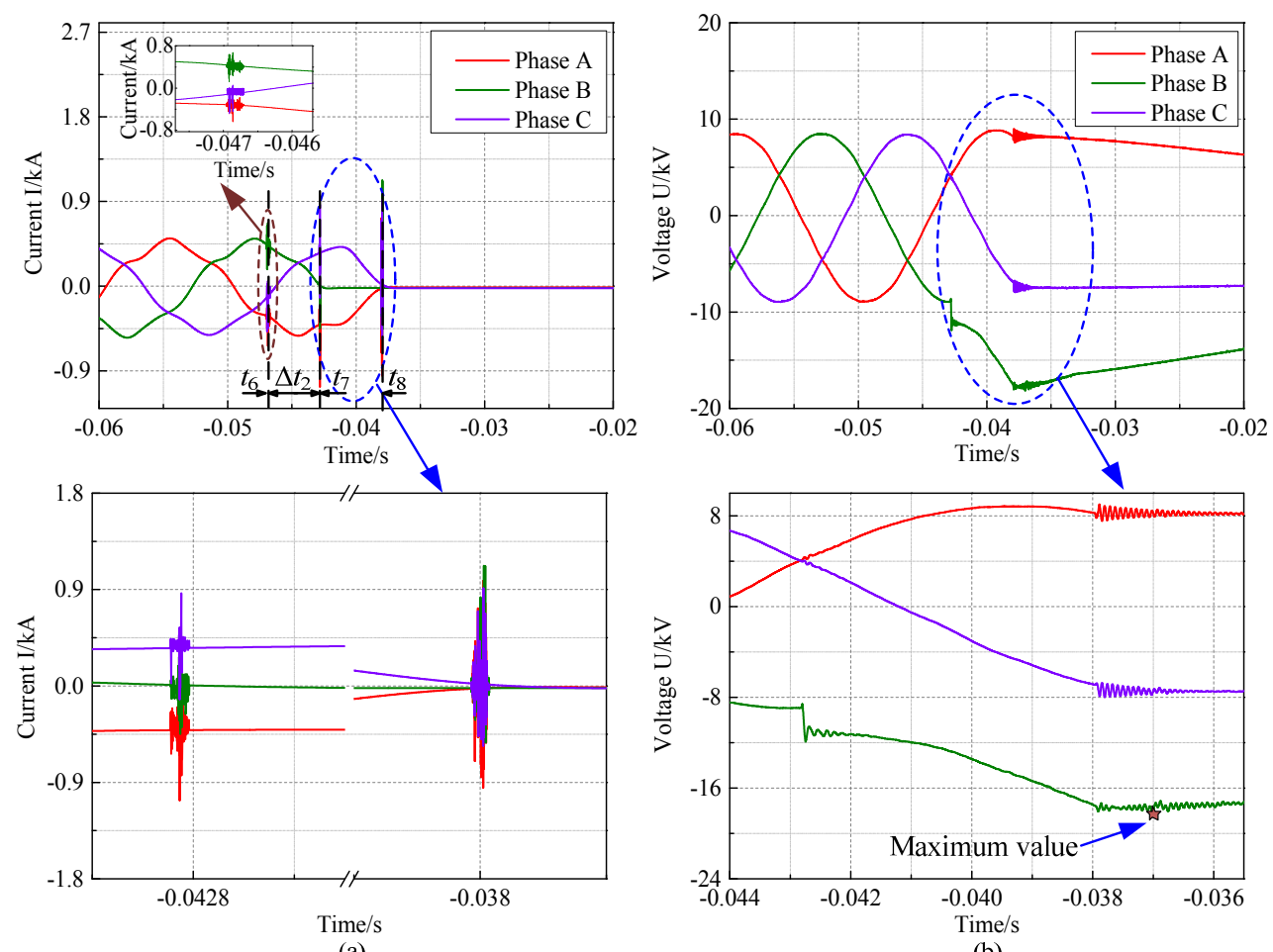

(a)

(b)

Figure 12. Waveforms of the opening current and capacitor voltage in Case 5. (a) Current waveform; and (b) voltage waveform.

\subsection{Case 6}

Before the switching-off operations in Case 6, \#653 is closed, and \#65302 and \#65303 are opened. The circuit breaker of this switching operation is \#65301. Figure 13a shows the opening current waveforms in Case 6 with phase selection. The strategy for opening shunt capacitor banks with phase selection is also addressed in Section 2. The breaker contacts of phase B start to separate $2.67 \mathrm{~ms}$ $\left(\Delta t_{3}=2.67 \mathrm{~ms}\right)$ later than its last current zero-crossing point at $t_{9}$, and phase B is the first-pole-to-clear. The transient currents of phase $A$ and phase $C$ are always equal, but in the opposite direction, after the current of phase $\mathrm{B}$ decreases to zero at the moment of $t_{10}$, which is also the time that the contacts of phase A and phase $\mathrm{C}$ start to separate. The breaking arc duration of phase B is $\Delta t_{4}=7.4 \mathrm{~ms}$ $\left(\Delta t_{4}=t_{10}-t_{9}\right)$. After a quarter of a cycle $(5 \mathrm{~ms})$, the currents of phase $\mathrm{A}$ and phase $\mathrm{C}$ both reach zero at the moment of $t_{11}$. Therefore, the power frequency extinguishing arcing still occurs in this case. Statistical results according to our field tests indicate that the breaking arc duration of the first-pole-to-clear (phase B in this test) is about $7.5 \mathrm{~ms}$, and the time error of the phase-controlled circuit breaker for opening shunt capacitor banks is below $\pm 0.3 \mathrm{~ms}$. 
Figure 13b illustrates the opening voltage waveform in Case 6. The maximum of the opening voltage in this case occurs in the first-pole-to-clear (phase B), and its value is $-12.83 \mathrm{kV}$ (1.57 p.u.). The residual charge of capacitors remains more than 30 power frequency cycles after the capacitors are disconnected.
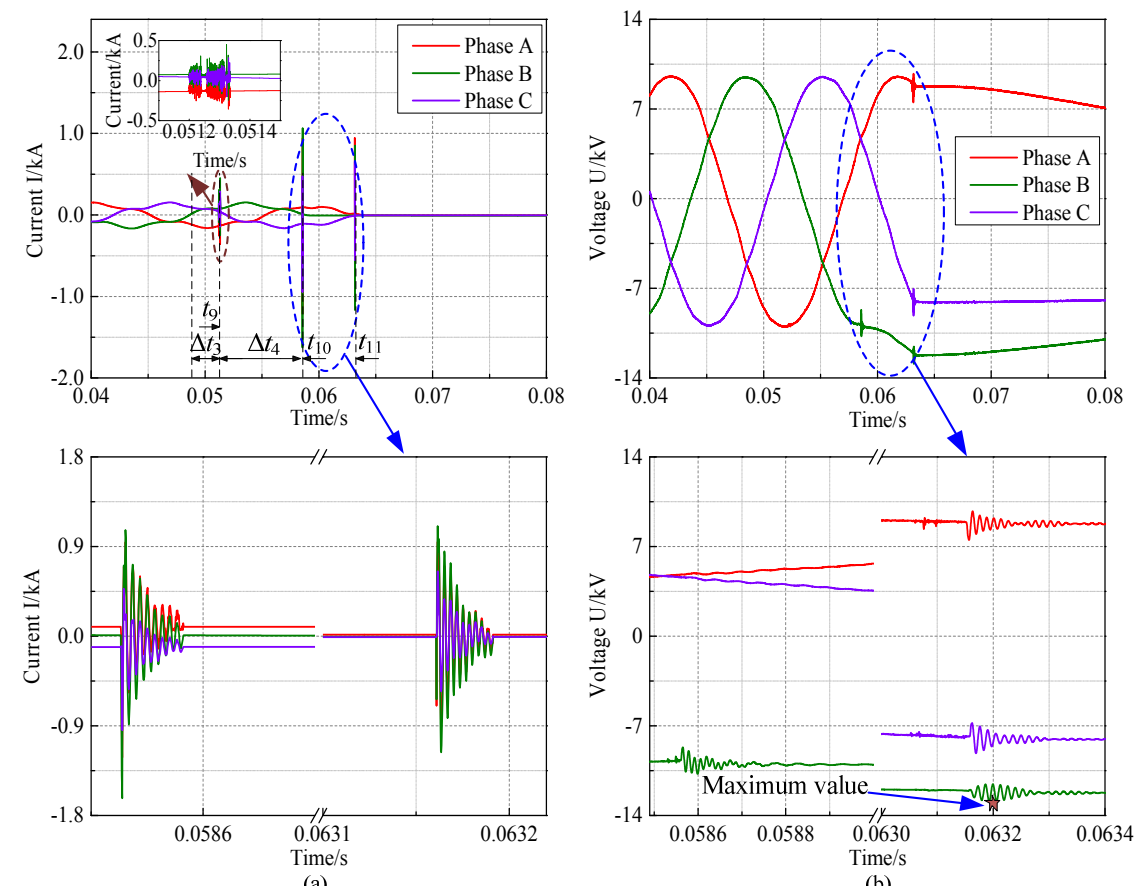

Figure 13. Waveforms of the opening current and capacitor voltage in Case 6. (a) Current waveform; and (b) voltage waveform.

\section{Conclusions}

Based on our previous work in this field [15,16], this study presents a complete comparison between ordinary VCBs and phase-controlled VCBs in the application of switching $10 \mathrm{kV}$ shunt capacitor banks through field tests. The following conclusions are drawn:

» The overcurrent of closing $10 \mathrm{kV}$ shunt capacitor banks was about $2.12 \mathrm{p}$.u. with phase selection, and it was far below than those of ordinary VCBs (4.04 p.u. for Case 1 and 4.49 p.u. for Case 2). Moreover, high-frequency voltage oscillation did not occur for switching on shunt capacitor banks when phase-controlled VCBs were used.

$\gg$ The overvoltage of opening $10 \mathrm{kV}$ shunt capacitor banks was about 1.57 p.u. with phase selection, and it was below those of ordinary VCBs (2.26 p.u. for Case 4 and 2.23 p.u. for Case 5).

$\gg \quad$ The arc duration of closing shunt capacitor banks without phase selection was about 1.0-4.5 ms. However, for the phase-controlled VCBs, the circuit breaker of the first-pole-to-clear was opened 2-3 ms later than its last current zero-crossing point, which result in an average of $7.5 \mathrm{~ms}$ arc duration of first-pole-to-clear.

$\gg \quad$ The time error of phase-controlled VCBs for opening and closing shunt capacitor banks was below $\pm 0.3 \mathrm{~ms}$. Furthermore, the higher arc duration increased the fracture gap distance of phase-controlled VCB contacts, and the probability of prestrike and re-ignition was reduced. This can contribute to keeping the power system safe and achieving steady operation.

Acknowledgments: This work was supported by the National Natural Science Foundation of China (51177182), the National Natural Science Foundation of China (51477018), the National Natural Science Foundation of China (51507019), and the Funds for Innovative Research Groups of China (51321063). 
Author Contributions: Wenxia Sima contributed to the research idea and theoretical analysis of switching shunt capacitor banks. Mi Zou designed the experiments, and drafted the manuscript. Qing Yang, Ming Yang and Licheng Li worked on the data analysis and revision of the manuscript. All authors have read and approved the final manuscript.

Conflicts of Interest: The authors declare no conflict of interest.

\section{References}

1. Dullni, E.; Shang, W.K.; Gentsch, D. Switching of capacitive currents and the correlation of restrike and pre-ignition behavior. IEEE Trans. Dielectr. Electr. Insul. 2006, 13, 65-71. [CrossRef]

2. Glinkowski, M.; Greenwood, A.; Hill, J.; Mauro, R.; Varneckes, V. Capacitance switching with vacuum circuit-breakers-A comparative-evaluation. IEEE Trans. Power Deliv. 1991, 6, 1088-1095. [CrossRef]

3. Jones, R.A.; Fortson, H.S. Consideration of phase-to-phase surges in the application of capacitor banks. IEEE Trans. Power Deliv. 1986, 1, 240-244. [CrossRef]

4. Witte, J.F.; DeCesaro, F.P.; Mendis, S.R. Damaging long term overvoltages on industrial apacitor banks due to transformer energization inrush currents. IEEE Trans. Ind. Appl. 1994, 30, 1107-1115. [CrossRef]

5. Bruns, D.P.; Newcomb, G.R.; Miske, S.A.; Taylor, C.W.; Lee, G.E.; Edris, A.A. Shunt capacitor bank series group shorting (CAPS) design and application. IEEE Trans. Power Deliv. 2001, 16, 24-32. [CrossRef]

6. Anderson, E.; Karolak, J.; Wisniewski, J. Application of modern switching methods in reactive power compensation systems. Prz. Elektrotechniczny 2012, 88, 1-5.

7. Bonfanti, I. Shunt Capacitor Bank Switching, Stressesand Test methods (2nd part) (Cigre WG 13-04). Electra 1999, 183, 13-41.

8. Mcgranaghan, M.F.; Reid, W.E.; Law, S.W.; Gresham, D.W. Overvoltage protection of shunt-capacitor banks using MOV arresters. IEEE Trans. Power Appar. Syst. 1984, 103, 2326-2336. [CrossRef]

9. Pflanz, H.M.; Lester, G.N. Control of overvoltages on energizing capacitor banks. IEEE Trans. Power Appar. Syst. 1973, 92, 907-915. [CrossRef]

10. Boehne, E.W.; Low, S.S. Shunt capacitor energization with vacuum interrupters-A possible source of overvoltage. IEEE Trans. Power Appar. Syst. 1969, 88, 1424-1443. [CrossRef]

11. Surge Protective Devices Committee. Surge protection of high-voltage shunt capacitor banks on AC power-systems survey results and application considerations. IEEE Trans. Power Deliv. 1991, 6, 1065-1072.

12. Das, J.C. Analysis and control of large-shunt-capacitor-bank switching transients. IEEE Trans. Power Appar. Syst. 2005, 41, 1444-1451.

13. Zadeh, M.K.; Hinrichsen, V.; Smeets, R.; Lawall, A. Field emission currents in vacuum breakers after capacitive switching. IEEE Trans. Dielectr. Electr. Insul. 2011, 18, 910-917. [CrossRef]

14. Smeets, R.P.P.; Thielens, D.W.; Kerkenaar, R.W.P. The duration of arcing following late breakdown in vacuum circuit breakers. IEEE Trans. Plasma Sci. 2005, 33, 1582-1588. [CrossRef]

15. Yang, Q.; Ouyang, S.; Sima, W.X.; Xi, S.Y.; Kang, H.F.; Yang, M. Mechanism of overvoltage induced by fast switching on-off $10 \mathrm{kV}$ shunt capacitors using vacuum circuit breakers. High Volt. Eng. 2014, 40, 3135-3140. (In Chinese)

16. Yang, Q.; Zhang, Z.H.; Sima, W.X.; Yang, M.; Wei, G.W. Field experiments on overvoltage caused by 12 kV vacuum circuit breakers switching shunt reactors. IEEE Trans. Power Deliv. 2015. [CrossRef]

17. CIGRE (International Council on Large Electric systems) Working Group A3, 07. Controlled Switching of HVAC Circuit Breaker: GUIDANCE for Further Applications Including Unloaded Transformer Switching, Load and Fault Interruption and Circuit-Breaker Updating; CIGRE: Paris, France, 2004.

18. Mahurkar, T.M.; Murali, M. Suppression of capacitor switching transients using symmetrical structure transient limiter [SSTL] and its applications. In Proceedings of the International Conference on Computation of Power, Energy, Information and Communication, Chennai, India, 16-17 April 2014.

19. Filion, Y.; Coutu, A.; Isbister, R. Experience with controlled switching systems (CSS) used for shunt capacitor banks: planning, studies and testing accordingly with CIGRE A3-07 Working Group Guidelines. In Proceedings of the Quality and Security of Electric Power Delivery Systems Conference, Montreal, PQ, Canada, 8-10 October 2003. 
20. Borghetti, A.; Napolitano, F.; Nucci, C.A.; Paolone, M.; Sultan, M.; Tripaldi, N. Transient recovery voltages in vacuum circuit breakers generated by the interruption of inrush currents of large motors. In Proceedings of the International Conference on Power Systems Transients (IPST2011), Delft, The Netherlands, 14-17 June 2011.

21. Ding, F.H.; Duan, X.Y.; Zou, J.Y.; Liao, M.F. Controlled switching of shunt capacitor banks with vacuum circuit breaker. In Proceedings of the International Symposium on Discharges and Electrical Insulation in Vacuum (ISDEIV 2006), Matsue, Janpan, 25-29 September 2006.

22. Ning, D.; Yonggang, G.; Jingsheng, Z.; Jirong, N.; Shuhua, Y.; Guozheng, X. Protections of overvoltages caused by $40.5 \mathrm{kV}$ vacuum circuit breakers switching off shunt reactors. High Volt. Eng. 2010, 36, 345-349. (In Chinese)

23. Roseburg, T.; Tziouvaras, D.; Pope, J. Controlled Switching of HVAC Circuit Breakers: Application Examples and Benefits. In Proceedings of the 61st Annual Conference for Protective Relay Engineers, College Station, TX, USA, 1-3 April 2008.

24. Reid, J.F.; Tong, Y.K.; Waldron, M.A. Controlled Switching Issues and the National Grid Company's Experience of Switching Shunt Capacitor Banks and Shunt Reactor; August Session; CIGRE: Paris, France, 1998; pp. 223-231.

25. Jones, S.; Gardner, K.; Brennan, G. Switchgear issue in deregulated electricity industries in Australia and New Zealand; August Session; CIGRE: Paris, France, 2000; pp. 1-6.

26. Nordin, R.; Holm, A.; Norberg, P. Ten Years of Experience with Controlled Circuit Breaker Switching in the Swedish Regional Network; August Session; CIGRE: Paris, France, 2002; pp. 21-23.

27. Li, D. Study on forepart re-strike rate of $35 \mathrm{kV}$ vacuum circuit breaker in the closing-opening process of capacitor group. High Volt. Eng. 2002, 28, 22-23. (In Chinese)

28. Yan, X.L.; Li, Z.B.; Wang, C.Y.; Liu, B.Y.; Wang, H. Analysis on characteristics of phase-selectable circuit breaker for switching capacitor banks in UHV power transmission project. Power Syst. Technol. 2014, 38, 1772-1778.

29. Liu, S.H. Analysis and simulation study on overvoltage of shunt power capacitor. Master's thesis, South China University of Technology, Guangdong, China, 2011. (In Chinese)

30. Zhong, X. Study on the transition process of closing shunt capacitors in $10 \mathrm{kV}$ power system. Master's Thesis, Chongqing University, Chongqing, China, 2010. (In Chinese)

31. Insulation Co-Ordination-Part I: Definitions, Principles and Rules; IEC Std. 60071-1:2006; IEC (the International Electrotechnical Commission): Geneva, Switzerland, 2006. 